\title{
Educação Profissional e Tecnológica Antes e depois da LDB de 1996
}

\author{
Sandra Terezinha Urbanetz \\ Paulo Cesar de Souza Ignácio*
}

\begin{abstract}
RESUMO: O texto faz uma reflexão inicial da trajetória da educação profissional e tecnológica desde a promulgação da Lei de Diretrizes e Bases da Educação (LDB), de 1996. Analisa alguns aspectos anteriores à LDB, bem como as forças políticas e as contradições nos diversos programas e projetos sobre a educação profissional e tecnológica. O que se visualiza é a falta de políticas consistentes, até porque as políticas educacionais permanecem atreladas a interesses que, muitas vezes, não visam à verdadeira democratização do conhecimento.
\end{abstract}

Palavras chave: LDB. Políticas e programas. Educação profissional.

\section{Professional and technological education}

Before and after the Legal guidelines and base's for education (LDB) of 1996

\begin{abstract}
: the text provides an initial reflection on the trajectory of professional and technological education since the promulgation of the LDB in 1996. It analyses some earlier aspects of the law, such as the political forces and the contradictions between the different programs and projects on professional and technological education. What we see is a lack of consistency in policies, as edu-
\end{abstract}

* Doutora em Educação. Professora do Instituto Federal de Educação, Ciência e Tecnologia do Paraná (IFPR), Campus Curitiba, Vice-coordenadora da Pós Graduação em Educação Profissional Técnica em Nível Médio e Coordenadora do Grupo de Pesquisa: Trabalho, Educação e Tecnologia Social - TRETS. Curitiba/PR Brasil. E-mail: <sandra.urbanetz@ifpr.edu.br>.

** Doutor em Educação. Professor Titular no Campus Juiz de Fora do Instituto Federal de Educação, Ciência e Tecnologia do Sudeste de Minas Gerais (IF Sudeste MG/JF), sucessor do Colégio Técnico Universitário da Universidade Federal de Juiz de Fora (CTU/UFJF). Em exercício de Colaboração Técnica junto ao Campus Curitiba do Instituto Federal de Educação, Ciência e Tecnologia do Paraná (IFPR). Juiz de Fora/MG - Brasil. E-mail:<paulo.c.ignacio@gmail.com>. 
cational policy remains tied to interests which very often are not concerned with the true democratization of knowledge.

Key words: Legal guidelines and base's for education (LDB). Policies and programs. Professional education.

\section{Educación profesional y tecnológica}

Antes y después de la LDB de 1996

RESUMEN: El texto presenta una reflexión inicial sobre el trayecto de la educación profesional y tecnológica desde que se promulgó la Ley de Directrices y Bases de la Educación (LDB), de 1996. Analiza algunos aspectos anteriores a la LDB, además de las fuerzas políticas y las contradicciones en los programas y proyectos sobre la educación profesional y tecnológica. Lo que se observa es la falta de políticas consistentes, incluso porque las políticas educativas siguen vinculadas a intereses que muchas veces no buscan la verdadera democratización del conocimiento.

Palabras clave: LDB. Políticas y programas. Educación profesional.

\section{Education professionnelle et technologique} Avant et aprés la LDB de 1996

RÉSUMÉ: Ce texte propose une réflexion initiale sur la trajectoire de l'éducation professionnelle et technologique depuis la promulgation de la Loi des Lignes Directrices et de Bases de l'Education, de 1996. Il analyse certains aspects antérieurs à la Loi, tout comme les forces politiques et les contradictions des divers programmes et projets concernant l'éducation professionnelle et technologique. Ce qui ressort est le manque de politiques consistantes, et ce du fait que ces politiques sont liées à des intérêts qui rarement ont pour but la démocratisation de la connaissance.

Mots-clés: LDB. Politiques et programmes. Education professionnelle. 


\section{Introdução}

$\mathrm{M}$ esmo antes da promulgação da Lei de Diretrizes e Bases da Educação(LDB) em 20 de dezembro de 1996 (Lei no 9.394, de 1996), o bloco no poder ${ }^{1}$, representado naquele momento no Estado capitalista brasileiro pelo governo do presidente Fernando Henrique Cardoso (FHC), já se movimentava no sentido de modificar o arcabouço jurídico da educação profissional e tecnológica, para adequá-la às novas funções definidas a partir da adoção do modelo econômico vigente, por meio do envio ao Congresso Nacional do Projeto de Lei (PL) nº 1.603, em 5 de março de 1996.

Essa iniciativa, portanto, se confunde com a tramitação ainda da nova LDB e se constitui na gênese do que um pouco mais tarde se configuraria como a Reforma da Educação Profissional, levada a efeito em 1997.

No plano mais geral do arcabouço jurídico da educação, o governo FHC demonstrou sua truculência e autoritarismo, ao desprezar todos os anos de discussão em torno da construção de uma nova LDB iniciados quase que imediatamente após a promulgação da Constituição Federal de 1988, com a entrada na Câmara do projeto do deputado Otávio Elísio, anos esses em que os setores da sociedade civil organizada ligados à educação se fizeram representar por meio do Fórum em Defesa da Escola Pública na LDB.

A trajetória desse projeto na Câmara dos Deputados inclui a aprovação por unanimidade na Comissão de Educação, Cultura e Desporto, em 28 de junho de 1990, do substitutivo do deputado Jorge Hage, sua passagem pela Comissão de Finanças, sua ida ao Plenário, seu retorno às comissões, para finalmente voltar ao Plenário para aprovação final, ocorrida na sessão do dia 13 de maio de 1993.

Nesse mesmo período, surgem projetos paralelos no Senado, como o do senador Darcy Ribeiro, que obtém aprovação na Comissão de Educação dessa Casa, decisão anulada porque a apreciação do projeto não fora incluída na pauta de convocação do Senado, o que o impedia de deliberar sobre o assunto. Nesse entreato, o texto aprovado na Câmara segue seu percurso e vai ao Senado, sendo designado como relator pela Comissão de Educação o senador Cid Sabóia, que, após muitas discussões com vários atores sociais, elabora um substitutivo. Esse substitutivo é aprovado na Comissão de Educação no Senado em dezembro de 1994 e é encaminhado ao Plenário.

\section{Imposições de uma visão mercadista}

No entanto, após a posse dos novos parlamentares em janeiro de 1995 em decorrência das eleições gerais de 1994, em que o governo FHC obtém a maioria no Congresso, o substitutivo do senador Cid Sabóia é considerado sob vários aspectos inconstitucional pela Comissão de Constituição e Justiça. O senador Darcy Ribeiro então apresenta substitutivo 
próprio, que após inserir algumas emendas tem sua última versão aprovada no Plenário do Senado em sessão do dia 8 de fevereiro de 1996 e é encaminhado de volta à Câmara dos Deputados. Lá, o deputado José Jorge é designado seu relator e, em sessão plenária realizada no dia 17 de dezembro de 1996, o projeto é aprovado. Segue então para a sanção presidencial. Esse célere percurso do substitutivo do senador Darcy Ribeiro sinaliza o desprezo do governo FHC à construção democrática do projeto de LDB da sociedade brasileira.

Já a formulação do PL nº 1.603, de 1996, que corria em paralelo à tramitação descrita anteriormente e que dispunha sobre educação profissional e a organização da Rede Federal de Educação Profissional, se deu no âmbito da, então, Secretaria de Ensino Médio e Técnico do Ministério da Educação (SEMTEC/MEC), tendo como origem basicamente dois documentos. O primeiro, da própria SEMTEC/MEC intitulado Planejamento político-estratégico 1995/1998, de maio de 1995, e o segundo, intitulado Educação profissional: um projeto para o desenvolvimento sustentado, da Secretaria de Formação e Desenvolvimento Profissional (Sefor) do Ministério do Trabalho (MTb), de agosto do mesmo ano.

Essa articulação do MEC com a Sefor/MTb situou claramente o PLํำ1.603, de 1996 no âmbito dos ajustes - na educação - ao novo padrão de acumulação capitalista que se instalava no país àquela altura, em substituição ao padrão taylorista/fordista, que, grosso modo, segundo Harvey (2000, p. 199), se caracterizava "por processos de trabalho e mercados mais flexíveis", por uma crescente mobilidade geográfica e por rápidas mudanças no padrão de consumo.

O PL previa mudanças substanciais no modelo de ensino técnico, sendo as principais, (i) a educação profissional passaria a abranger três níveis, sendo: 1) básico, 2) técnico e 3) tecnológico; (ii) seria organizado independentemente do curso de ensino médio, o que, na prática, resultaria na separação da formação geral e específica; (iii) organização curricular por meio de módulos para os níveis técnico e tecnológico, cada qual com caráter de terminalidade, dando direito a certificados intermediários de qualificação profissional para seus concluintes.

A educação profissional de nível básico seria uma modalidade de educação não formal, de duração variável e destinar-se-ia à qualificação e requalificação básicas de trabalhadores, independentemente de escolaridade prévia, que poderia ser ministrada em instituições especializadas ou no ambiente de trabalho e conferiria aos seus concluintes um certificado de qualificação profissional. O nível técnico da educação profissional teria currículo próprio organizado de maneira independente do ensino médio, podendo ser oferecido concomitante ou sequencialmente a este e destinar-se-ia a proporcionar uma habilitação profissional. Os currículos seriam estruturados preferencialmente sob a forma de módulos, constituídos por um conjunto de disciplinas ou conteúdos articulados, tendo cada qual o caráter de terminalidade para efeito de qualificação profissional, dando direito a um certificado de qualificação. O conjunto de certificados correspondentes aos módulos de um curso técnico equivaleria ao diploma de técnico. A educação profissional de nível tecnológico compreenderia os cursos de tecnologia de nível superior aos egressos dos cursos médio e técnico e confeririam o diploma de Tecnólogo. 
O PL instituía, ainda, nos Centros Federais de Educação Tecnológica (CEFETs) e nas Escolas Técnicas Federais (ETFs) e Escolas Agrotécnicas Federais (EAFs), ainda existentes à época, os Conselhos de Administração e de Ensino, cujos membros seriam nomeados pelo ministro da Educação. O Conselho de Administração seria constituído por representantes do MEC, dos docentes, dos discentes, dos servidores técnico-administrativos, sendo presidido pelo diretor-geral da instituição. O Conselho de Ensino seria constituído por representantes dos empresários e trabalhadores, responsáveis pelos setores de ensino, de relações empresariais e dos cursos ministrados pela instituição, sendo presidido também pelo diretor-geral do estabelecimento. Entre as atribuições dos conselhos, destacamos: (i) apresentar e acompanhar a proposta orçamentária e indicar e implementar novas formas de captação de recursos; (ii) deliberar sobre a validade e oportunidade das habilitações oferecidas pela instituição, face às necessidades do setor produtivo, identificadas por meio de sistema de monitoramento de demanda; e (iii) elaborar conjuntamente a lista tríplice, da qual o ministro da Educação escolheria e nomearia o diretor-geral do estabelecimento.

Na exposição de motivos nº 37, de 4 de março de 1996 ao presidente, elaborada pelo ministro da Educação Paulo Renato e que acompanha a mensagem de envio do PL ao Congresso, são explicitadas as razões do governo para tais medidas. A primeira delas evidentemente é a de que o projeto se integraria à proposta de governo de FHC e representaria um "avanço na modernização do ensino profissional do país", com vistas à "retomada do desenvolvimento", tendo como pano de fundo a "globalização da economia", que impõe mudanças nas políticas de formação profissional, em face dos avanços tecnológicos e das novas demandas do setor produtivo (BRASIL, 1996a, p. 1).

Entendia o governo que essa nova conformação dada à educação tecnológica - que na verdade a reduzia à educação profissional ${ }^{2}$ - atenderia às exigências do "moderno mercado de trabalho", que exige flexibilidade, qualidade e produtividade do trabalhador de novo tipo e se apresentaria como "complementar à Educação Básica e alternativa à Educação Superior" (BRASIL, 1996a, p. 1).

A organização do currículo em módulos, segundo o governo, daria "corpo às propostas de flexibilidade e de educação permanente". Essa organização, por compreender etapas progressivas e articuladas, traçaria:

\begin{abstract}
itinerários cada vez mais elevados de competência para o trabalho, possibilitando: a) um processo contínuo de qualificação, especialização e aperfeiçoamento profissional; b) atendimento às necessidades do mercado de trabalho, por meio de formação diversificada e continuada e c) desenvolvimento de uma formação permanente e flexível, capaz de oferecer diversas e reiteradas oportunidades de realização individual e coletiva (BRASIL, 1996a, p. 2).
\end{abstract}

Para o alcance desses objetivos, seria então organizada uma rede específica de educação profissional, eufemisticamente denominada de Rede Federal de Educação Tecnológica 
composta pelas ETFs e suas unidades descentralizadas, pelas EATs, existentes até então, e pelos CEFETs e também suas unidades descentralizadas.

Tal projeto foi objeto de duras críticas pelos setores da sociedade civil organizada ligados ao ensino técnico. Em um "Manifesto aos Parlamentares", várias entidades sindicais e estudantis ligadas ao ensino técnico e à educação em geral no país questionaram principalmente: 1) o término da formação integral do técnico; 2) a oferta do ensino profissional voltado exclusivamente às necessidades do mercado; 3) a quebra da interdisciplinaridade com a introdução do currículo por módulos; 4) a possibilidade de financiamento de iniciativas privadas com recursos públicos; e 5) a quebra da autonomia administrativa, didática e pedagógica pela introdução dos Conselhos de Administração e de Ensino.

Inúmeras outras manifestações de repúdio ao PL nº 1.603, de 1996 emanaram de diversas entidades, como do Sindicato Nacional dos Servidores da Educação Federal de $1^{\circ}$, $2^{\underline{0}}$ e $3^{0}$ Graus (SINASEFE) e Associação Nacional dos Docentes das Instituições de Ensino Superior - Sindicato Nacional (ANDES-SN), alertando basicamente para o fato de que o PL n 1.603 , de 1996 se configuraria numa ação inconsequente para o futuro da educação brasileira ao transformar as instituições de educação tecnológica em meras agências de treinamento fragmentado e inorgânico de mão de obra, demarcado exclusivamente pelas necessidades mais estreitas do capital, o que retiraria do país o potencial para uma inserção autônoma e soberana no cenário de uma economia internacional globalizada e altamente predatória.

Na verdade, como afirma Kuenzer (1997), a tentativa de acomodar diferentes concepções de grupos que pertencem ao mesmo governo - o MEC e o MTb -, sobre a mesma preocupação de integrar a economia brasileira à globalização e às decorrentes demandas de formação de um trabalhador de novo tipo, resultarou no desastrado PL no 1.603 , de 1996, que da data de entrada na Câmara (07/03/1996) até os dias 15 e 16 de maio daquele mesmo ano, quando foi realizado em Brasília um seminário promovido pela Comissão de Educação da Câmara para sua apreciação, havia recebido 212 emendas, sendo 156 modificativas ou substitutivas, 23 aditivas e 33 supressivas aos seus 34 artigos originais.

De um lado, no âmbito do MTb, por intermédio da Sefor, com Nassim G. Mehedff à sua frente, é empreendido um amplo processo de discussão tendo como pano de fundo a necessidade de se pensar a formação do "cidadão produtivo" em face das exigências da nova etapa de desenvolvimento das forças produtivas. A partir dessas discussões, é elaborado o documento Educação profissional: um projeto para o desenvolvimento sustentado, em que, segundo Kuenzer (1997), a Sefor chama para si a tarefa de consolidar uma política pública de trabalho e de educação profissional, tendo como clientela privilegiada os desempregados e os excluídos, para que houvesse a integração entre as três funções do MTb: intermediação, pagamento de benefícios e qualificação/requalificação profissional. 


\section{Direito do cidadão versus mercado de trabalho}

A proposta da Sefor entendia que a educação profissional não se confunde com a educação básica, incluído o ensino médio, apesar de se articular com todos os níveis de educação, não a substituindo, portanto; enquanto esta teria como foco os direitos universais do cidadão, aquele teria como foco o mercado de trabalho, com o objetivo de dar condições aos indivíduos de se manterem em um mercado cada vez mais competitivo e em contínua transformação por meio de estratégias contínuas de educação permanente.

Por outro lado, no âmbito do MEC, por meio da SEMTEC, tomava corpo uma discussão cujo eixo central era a função que as ETFs, EAFs e CEFETs estariam desempenhando na educação dos jovens, tendo como referencial de análise o significado do ensino médio e a exigência de maior "racionalidade" na aplicação dos recursos - em face da diminuição do fundo público - visando a uma melhoria na relação custo/benefício para a manutenção e ampliação do ensino médio.

A discussão teve como origem o considerável aumento da demanda pelo ensino médio e o custo considerado muito elevado das ETFs e das EAFs, que teriam adquirido em razão da boa formação acadêmica que ofereciam - um caráter propedêutico, segundo avaliação feita por consultores do Banco Internacional para Reconstrução e Desenvolvimento (BIRD) e de instituições públicas nacionais. Ou seja, segundo essas avaliações, o governo estaria "desperdiçando" os parcos recursos que poderiam ser utilizados na manutenção e ampliação do ensino médio, em umas poucas escolas que teriam se "desviado" do seu objetivo e, em vez de estarem atendendo jovens que teriam necessidade e interesse de ingressar imediatamente no mercado de trabalho, estariam atendendo jovens da "elite", ou que almejavam se tornar dessa elite, cujo objetivo era o ingresso no ensino superior. Como pano de fundo dessa avaliação, estaria um dos pontos críticos do ensino médio apontado pelos consultores: a eterna indefinição quanto ao caráter terminal ou propedêutico desse nível de ensino (IGNÁCIO, 2000, p. 193-194).

Tendo como preocupação básica, então, a "racionalização" na aplicação dos recursos, de modo a possibilitar a ampliação da oferta de ensino médio, o MEC (BRASIL, 1995) toma como problema a ser resolvido o projeto político-pedagógico das ETFs, EAFs e CEFETs e aponta como uma das soluções a separação da formação acadêmica da formação profissional, tanto do ponto de vista conceitual quanto operacional. Essa intenção, juntamente com outras, é manifestada de forma bastante clara no documento Planejamento político-estratégico para 95/98 do MEC, no item 3 das ações básicas relativas ao ensino médio:

3. Redefinir a estratégia de gestão da rede federal de educação tecnológica para: Separar, do ponto de vista conceitual e operacional, a parte profissional da parte acadêmica;

Dar maior flexibilidade aos currículos das escolas técnicas de forma a facilitar a adaptação do ensino às mudanças no mercado de trabalho; 


\begin{abstract}
Promover a aproximação dos núcleos profissionalizantes das escolas técnicas com o mundo empresarial, aumentando o fluxo de serviços entre empresas e escolas;

Progressivamente, encontrar formas jurídicas apropriadas para o funcionamento autônomo e responsável das escolas técnicas e CEFETs e, ao mesmo tempo, estimular parcerias para financiamento e gestão;

Estabelecer mecanismos específicos de avaliação das escolas técnicas para promover a diversificação dos cursos e a integração com o mercado de trabalho. (BRASIL, 1995, p. 22).
\end{abstract}

Essa "redefinição de estratégia" visava dar conta dos supostos problemas já apontados pelo MEC no mesmo documento (BRASIL, 1995, p. 19-20), quais sejam: i) a extrema rigidez da vertente profissional do ensino médio; ii) a necessidade de flexibilizá-la ampliando a oferta de carreiras terminais focalizadas nas demandas do setor produtivo; iii) a inadequação das escolas de "vocação acadêmica" para o oferecimento de cursos profissionais; e iv) a escassez de recursos para a ampliação do ensino médio.

Assim, atropelando as discussões que vinham acontecendo no âmbito da Sefor/MTb sobre educação profissional e sem nenhuma consulta aos segmentos diretamente envolvidos com o ensino técnico, antecipando-se mesmo à conclusão e definição da nova LDB, o MEC, por meio de uma equipe interna, elabora o PL e o encaminha à Câmara onde recebe

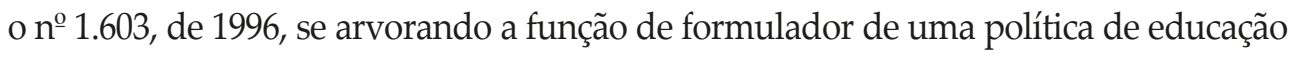
profissional e de articulação com os outros setores responsáveis por essas formulações, extrapolando claramente sua competência, batendo de frente com as competências do MTb e do setor produtivo (KUENZER, 1997).

Essa mesma autora apresenta, como razões desse atropelo, o acordo firmado entre o MEC e o BIRD, anunciado pelo próprio ministro à época, Paulo Renato, na imprensa no dia 4 de março de 1996, por ocasião do lançamento do Programa de Educação Profissional pelo presidente da República, acordo que exigia como contrapartida do MEC ao desembolso do BIRD o ajuste do arcabouço jurídico normativo relativo a essa modalidade de ensino. O BIRD, assim como outras instituições financeiras multilaterais, vincula a liberação de recursos à elaboração e execução de programas de ajustes e reformas que tenham como pressupostos os princípios defendidos por este, mormente os que dizem respeito à redução do papel do Estado no financiamento das políticas públicas sociais e a consequente busca por fontes alternativas de recursos (leia-se privatizações dos serviços públicos), a adoção do princípio da equidade em substituição à universalidade, a utilização do conceito burguês de competência - que transfere para a esfera individual a responsabilidade por condições históricas socialmente construídas - que, juntamente com outros princípios, nos permitem afirmar ter sido o PL no 1.603, de 1996 um sinal vigoroso da filiação do Estado brasileiro às políticas neoliberais, no caso específico, do campo da educação:

Embora síntese precária de duas concepções diferentes, entre as quais a do MTB é mais avançada com relação a esta etapa que o capitalismo atravessa, o PL 1.603, de 
1996 reflete, sem sombra de dúvida, a política neoliberal que caracteriza o Estado brasileiro neste momento histórico, e que é a expressão superestrutural da reorganização produtiva, por meio da qual o país se articula ao movimento mais amplo da globalização da economia, que exige racionalização do uso dos recursos finitos, redução da presença do Estado no financiamento das políticas sociais e aumento da flexibilidade, qualidade e produtividade no sistema produtivo. (KUENZER, 1997, p. 66).

O fato de ser calcado nesses princípios foi o que suscitou as inúmeras críticas ao PL, que o apontavam como conceitualmente equivocado, anacrônico e politicamente incorreto face a uma política de desenvolvimento autônomo e soberano e que se referiam sempre à dissociação entre o ensino médio e o ensino técnico, à transferência de verbas públicas para a iniciativa privada, ao foco exclusivo no mercado de trabalho eao comprometimento da autonomia administrativa e didático-pedagógica, que eram, entre outros, os aspectos mais polêmicos do PL.

A promulgação da nova LDB em 20 de dezembro de 1996, de caráter minimalista e desregulamentador como denunciou Saviani (1998), corroborava a estratégia do governo de impor pelo alto seu projeto preconcebido de sociedade, pois demandava ações regulamentadoras, que foram executadas autocraticamente por meio de decretos, portarias, resoluções e medidas provisórias. Nesse sentido é que o governo, em fevereiro de 1997, retirou estrategicamente o PL do Congresso e, com o objetivo manifesto de regulamentar os artigos da nova LDB relativos à educação profissional, publica em 17 de abril de 1997 o Decreto nº 2.208, seguido do art. 44 da Medida Provisória nº 1.549-29, de 16 de abril de 1997 e da Portaria do MEC nํo646, de 14 de maio de 1997, acabando, na verdade, por impor a reforma que pleiteava desde a elaboração do PL no 1.603, de 1996.

Paralelamente a essa publicação, o governo federal negocia junto ao BIRD um empréstimo para financiamento da educação profissional, indicando a continuidade da dependência histórica do país aos interesses privatistas hegemônicos. Nesse contexto, é criado o Programa de Expansão da Educação Profissional (Proep), que responsabiliza estados e municípios pela implantação de unidades e centros de educação profissionalizante, incentivando as parcerias entre as esferas públicas e privadas ${ }^{3}$.

Nesse sentido, o Decretonํํ․208, de 1997, além de conceber a separação entre a educação profissional eo ensino médio, confirmou a esfera educacional como possibilidade para o desenvolvimento da economia de mercado transformando, ainda, a educação profissional em um sistema paralelo, intensificandoa dualidadejá existentee há muito discutida por vários autores.

\section{Problemas não resolvidos}

Sete anos depois, em 23 julho de 2004, após intensas manifestações e a eleição do presidente Luiz Inácio Lula da Silva, é publicado o Decreto nº 5.154, revogando o Decreto no 2.208, de 1997 e dando uma nova regulamentação aos artigos da LDB que tratam da educação 
profissional e tecnológica ( $\$ 2^{2}$ do art. 36 e os artigos 39 a 41$)^{4}$. No entanto, mesmo apresentando correções nas distorções provenientes da reforma realizada pelo governo anterior, alguns autores apontam os problemas que ainda vivenciamos.

Conforme Ciavatta e Ramos (2011, p. 33-34):

Nossa análise não elide a importância da profissionalização para os jovens, nem a necessidade de se avançar o pensamento sobre o currículo do ensino médio, ultrapassando a marca conteudista e/ou tecnicista que o caracteriza. Mas a sustentação dessas políticas tem sido, notadamente, de cunho economicista e pragmático, distinguindo-se dos princípios filosóficos e ético-políticos que sustentaram tanto a defesa da revogação do Decreto n 2.208, de 1997 quanto a concepção de ensino médio integrado como travessia para a politecnia.

Percebe-se que os avanços conseguidos e incorporados à LDB não conseguiram efetivar a organicidade pretendida, mantendo a formação dos trabalhadores atrelada aos interesses imediatos do mercado, perdendo, com isso, a possibilidade de efetivar uma educação que, segundo Araujo (2006, p. 195):

\begin{abstract}
interessa aos trabalhadores e que se articula com um projeto contra-hegemônico, de socialismo. Nos perspectivamos, portanto, nos conceitos de politecnia e de escola unitária, categorias que sintetizam uma perspectiva de formação que tem o homem, e não o mercado, como principal referência.
\end{abstract}

Com o Decreto nº 5.154, de 2004, mantém-se a possibilidade de oferta de cursos téc-

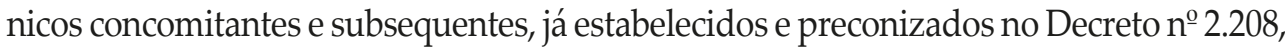
de 1997, além de ofertar o ensino médio integrado à educação profissional, porém com os limitadores de financiamento das propostas.

Nesse sentido, a polêmica permanece e, em meio a isso, tem-se a promulgação do Decreto n⿳0 6.302, de 2007, que institui o Programa Brasil Profissionalizado com o objetivo de: "estimular o ensino médio integrado à educação profissional, enfatizando a educação científica e humanística, por meio da articulação entre formação geral e educação profissional no contexto dos arranjos produtivos e das vocações locais e regionais." (BRASIL, 2007).

Esse programa não receberia nenhuma crítica se não evidenciasse mais uma vez o que Frigotto, Ciavatta e Ramos (2005, p. 4) indicam: “a política de educação profissional [destinada a jovens e adultos trabalhadores] processa-se mediante programas focais e contingentes", como exemplos o Programa Nacional de Integração da Educação Profissional com a Educação Básica na Modalidade de Educação de Jovens e Adultos (Proeja) e o Programa Nacional de Inclusão de Jovens (ProJovem), entre outros. 


\section{Considerações finais}

Vimos, portanto, que nesses 20 anos de existência de nossa LDB a educação profissional e tecnológica sofreu revezes que, em alguns casos, foram revertidos sob a pressão da sociedade civil organizada. Em um primeiro momento, em razão de seu caráter minimalista, o bloco no poder implantou pelo alto, por meio de decretos e portarias regulamentadoras, os ajustes que atendiam aos interesses do capital e seus aliados históricos, embora se afirmasse que se miravam os interesses dos jovens e da sociedade. Em um segundo momento, incorporaram esses ajustes ao próprio corpo da lei.

No entanto, em nenhum desses momentos, como é evidente pela própria constituição do bloco no poder, buscou-se atacar os problemas estruturais da educação em geral e da educação profissional e tecnológica em especial, porque isso significaria ter que encarar os problemas estruturais da própria formação social e econômica brasileira, e a opção das forças políticas que se hegemonizam no país não é a de construir uma alternativa possível, mas a de tentar soluções temporárias e conjunturais para os problemas estruturais de nossa sociedade capitalista. Exatamente daí é que surgem os inúmeros programas que vêm e vão, em detrimento de políticas de Estado estruturantes.

Ou seja, infelizmente os avanços conseguidos foram poucos e, em vista das propostas em pauta na atualidade, a perspectiva que se avista para a educação em geral e para a educação profissional, em específico, não é muito animadora.

Recebido em junho de 2016 e aprovado em agosto de 2016

\section{Notas}

1 A respeito do conceito de "bloco no poder", ver Poulantzas (1977) e Pinto e Balanco (2014).

2 Neves (1999, p. 11) faz uma delimitação clara entre os campos da educação técnica/tecnológica e profissional quando afirma que: "diferentemente da natureza mediatamente desinteressada (grifo nosso) da escola em relação ao trabalho, a educação profissional tem uma relação imediatamente interessada em relação ao trabalho, ou seja, ela se propõe a efetivar uma educação continuada para a readaptação, reciclagem e aperfeiçoamento permanente de toda a população economicamente ativa em face das repercussões econômicas e político-sociais da difusão acelerada de inovações tecnológicas neste século."

3 A respeito do PROEP ver BRASIL (1997a) e IGNÁCIO (2000, p. 208-210).

4 Em 16 de julho de 2008, os aspectos mais importantes do Decreto oㅜ 5.154, de 2004 acabaram incorporados à LDB por meio da Lei nº 11.741. 


\section{Referências}

ARAUJO, Ronaldo Marcos de Lima. A regulação da educação profissional do governo Lula: conciliação de interesses ou espaço para a mobilização? In: GEMAQUE, Rosana Maria Oliveira; LIMA, Rosângela Novaes (Org.). Políticas públicas educacionais: o governo Lula em questão. Belém: Cejup, 2006. p. 191-213.

BRASIL. Exposição de Motivos nº. 37, de 4 de março de 1996, do Senhor Ministro de Estado da Educação e do Desporto. Brasília, DF, 1996a

. Lei nº 9.394, de 20 de dezembro de 1996. Estabelece as diretrizes e bases da educação nacional. Diário Oficial da União, Brasília, DF, 23 dez. 1996b.

. Projeto de Lei no 1.603. Brasília, DF: Câmara dos Deputados, 1996c.

. PROEP - Programa de Expansão da Educação Profissional: orientação às IFETs para preparação do Plano de Implantação da Reforma. Brasília, DF: SEMTEC/MEC, 1997a.

. Medida Provisória nº 1.549-29, de 15 de abril de 1997. Dispõe sobre a organização da Presidência da República e dos Ministérios, e dá outras providências. Diário Oficial da União, Brasília, DF, 16 abr. $1997 \mathrm{~b}$.

BRASIL. Ministério da Educação(MEC). Planejamento Político-Estratégico: 1995/1998. Brasília, DF: MEC, 1995.

. Ministério da Educação (MEC). Portaria n⿳0 646, de 14 de maio de 1997. Regulamenta a implantação do disposto nos artigos 39 a 42 da Lei Federal n 9.394, de 1996 e no Decreto Federal nº 2.208, de 1997 e dá outras providências (trata da rede federal de educação tecnológica). Brasília, DF: MEC, 1997.

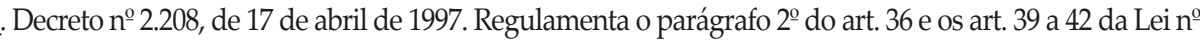
9.394, de 20 de dezembro de 1996, que estabelece as diretrizes e bases da educação nacional. Diário Oficial da União, Brasília, DF, 18 abr. 1997.

. Decreto $n^{\circ} 5.154$, de 23 de julho de 2004. Regulamenta o $\S 2^{\circ}$ do art. 36 e os arts. 39 a 41 da Lei $n^{\circ}$ 9.394, de 20 de dezembro de 1996, que estabelece as diretrizes e bases da educação nacional, e dá outras providências. Diário Oficial da União, Brasília, DF, 26 jul. 2004.

. Decreto nº 6.302, de 12 de dezembro de 2007. Institui o Programa Brasil Profissionalizado. Diário Oficial da União, Brasília, DF, 13 dez. 2007.

CIAVATTA, Maria, RAMOS, Marise. Ensino médio e educação profissional no Brasil: dualidade e fragmentação. Revista Retratos da Escola, v. 5, n. 8, p. 27-41, 2011.

FRIGOTTO, Gaudêncio; CIAVATTA, Maria; RAMOS, Marise. A política de educação profissional no governo Lula: um percurso histórico controvertido. Educ. Soc., v. 26, n. 92, p. 1087-1113, 2005.

HARVEY, David. Condição pós-moderna: uma pesquisa sobre as origens da mudança cultural. 9. ed. São Paulo: Edições Loyola, 2000.

IGNÁCIO, Paulo César de Souza. Da educação tecnológica à formação profissional: a reforma do ensino técnico em questão. Dissertação (Mestrado em Educação), Universidade Federal Fluminense, Niterói, 2000. 246 p.

KUENZER, Acácia Zeneida. Ensino médio e profissional: as políticas doestadoneoliberal. São Paulo: Cortez, 1997.

NEVES, Lúcia Maria Wanderley. Brasil ano 2000: uma nova divisão de trabalho na educação. Rio de Janeiro: Papéis e Cópias, 1999.

PINTO, Eduardo Costa; BALANCO, Paulo. Estado, bloco no poder e acumulação capitalista: uma abordagem teórica. Revista de Economia Política, v. 34, n. 134, p. 39-60, 2014.

POULANTZAS, Nicos. Poder político e classes sociais. São Paulo: Martins Fontes, 1977.

SAVIANI, Dermeval. Da nova LDB ao novo plano nacional de educação: por uma outra política educacional. Campinas: Autores Associados, 1998. 